\title{
A Novel Imprinted Gene (Sp-PoI) with Sex-specific SNP Locus and Sex-biased Expression Pattern Provides Insights into the Gonad Development of Mud Crab (Scylla Paramamosain)
}

\section{Ardavan Farhadi}

Shantou University Marine Biology Institute

Shi Xi

Shantou University Marine Biology Institute

Yin Zhang

Shantou University Marine Biology Institute

Huaiping Zheng

Shantou University Marine Biology Institute

Shengkang $\mathrm{Li}$

Shantou University Marine Biology Institute

Yueling Zhang

Shantou University Marine Biology Institute

Mhd Ikhwanuddin

Universiti Malaysia Terengganu

Hongyu Ma ( $\sim$ mahy@stu.edu.cn )

Shantou University https://orcid.org/0000-0003-2299-503X

\section{Research}

Keywords: Imprinted gene, Gonad differentiation, Mud crab, Sp-Pol, Sex-specific SNP

Posted Date: May 26th, 2021

DOI: https://doi.org/10.21203/rs.3.rs-524084/v1

License: (c) (1) This work is licensed under a Creative Commons Attribution 4.0 International License.

Read Full License

Version of Record: A version of this preprint was published at Frontiers in Marine Science on August 19th, 2021. See the published version at https://doi.org/10.3389/fmars.2021.727607. 


\section{Abstract}

Background: We previously discovered a potential sex-specific single nucleotide polymorphism (SNP) locus named SNP1888 in mud crab (Scylla paramamosain).

Methods: In this study, we first verified SNP1888 to be truly a female-specific locus and then we identified a novel imprinted gene (designated as Sp-Pol) at the upstream of SNP1888 (SNP1888 is located at the 3'UTR of $S p$-Pol). Moreover, SNP1888 together with $S p$-Po/ were mapped on LG32 of a high-density genetic map.

Results: Phylogenetic analysis showed that $S p-P o /$ may need to be classified as a new gene family due to the very low sequence identity with other known genes. $S p$-Po/ was expressed at a higher level in gonads compared to other tissues and its expression level in the testis was much higher than in the ovary. Coincidentally, mono-allelic expression was observed in the ovary. Moreover, $S p$-Pol exhibited sex-biased expression with approximately 3- to 4-fold higher in males than in females at fifth (C5) and sixth (C6) crablet stages. During the zoeae development, $S p$-Po/had the highest expression at the zoea I stage. After unilateral eyestalk ablation, the expression level of $S p$-Po/ significantly increased in testis and hepatopancreas in males, while it was downregulated in the hepatopancreas of females. Fluorescence in situ hybridization (FISH) assay revealed that $S p$-Po/ transcripts were strongly localized in the epithelia of seminiferous tubules of the testis and in the ovary it was detected in the oogonium cells.

Conclusion: These results demonstrated that $S p-P o /$ may play important roles in the sexual development of S. paramamosain.

\section{Background}

Mud crab (Scylla paramamosain) is widely distributed in the south-eastern coastal area of China [1, 2]. This species is an economically and ecologically important species, and its cultivation is increasing to meet the demands of the market [3]. In China, S. paramamosain culture industry has been developing rapidly and its aquaculture production reached 138 thousand tons [4]. Male and female S. paramamosain exhibit different growth performances at different growth stages, which is important in artificial selective breeding and farming [3]. In hatcheries, females are considered more valuable than males for increasing the size of the population since males can copulate with more females with no negative effect on the percentage of berried females [5]. Meanwhile, the price of females with mature ovary is much higher than males. In addition, male and female $S$. paramamosain have different biochemical compositions, nutritional value, and flesh quality [2]. Mono-sex culture and controlling the sexual differentiation can open a new avenue of $S$. paramamosain culture industry. However, the mechanisms underlying sexual development of $S$. paramamosain remain unclear. Therefore, understanding the genetic mechanism of sexual development is necessary for effective production of larvae either for restoring wild populations or for aquaculture purposes. 
Sexual development includes sex determination, sexual differentiation, and sexual maturation processes. Sexual development begins with a sex-specific genetic cascade mediated through a chromosomal mechanism of sex determination [6]. The sex-determination system in true crabs (Brachyura) is controversial, with early karyotyping studies suggest an XY-XX sex-determination system [7], but recently genetic linkage map and sex-specific markers revealed the existence of both ZZ/ZW and XY/XX mechanisms [8-11]. Recently, various genetic techniques have been successfully applied to identify the sex-specific DNA sequences and markers in crabs. Restriction-site associated DNA sequencing (RAD-seq) has been successfully applied to develop sex-specific markers in several crab species $[9,10]$.

After sex has been determined a complex process of sexual differentiation ensues, resulting in sexspecific phenotypic development [6]. Crustacean female sex hormone (CFSH) and insulin-like androgenic gland hormone $(I A G)$ are the two major hormones that regulate the sexual differentiation of female and male crustaceans $[12,13]$. Androgenic gland (AG) ablation and $I A G$ silencing resulted in full sex reversal from male to female (feminization) in Macrobrachium rosenbergii $[12,14]$. The "eyestalk-AG-testis" endocrine axis plays a very important role in the regulatory mechanism of sex in male decapods. However, the mechanisms underlying the regulation of sexual differentiation and most of the key factors upstream and downstream the IAG in the "eyestalk-AG-testis" endocrine axis [15] are still poorly understood. For several years, scientists believed that the AG is the only key regulator of primary and secondary sexual characters in male decapods. Recently, several sex-related genes have been identified via transcriptomic analysis in decapods $[16,17]$, suggesting that sexual differentiation in decapods is more complicated than previously expected. These sex-related genes include different types, namely CFSH, Sxl, Fru, Fem-1, Tra, Tra-2, Dsx, Mab-3, Sry, Sox9, Foxl2, Wnt4, and Dmrt1 [18-20]. For example, it has been documented that CFSH, Sox, DSX, SIX,Dmrt, GEM, and Fem-1 regulate the expression of IAG. IAG expression is negatively regulated by GEM, Fem-1, and $C F S H$ [21-24]. In contrast, $S / x, D s x$, and Dmrt silencing significantly decrease the expression of $I A G$ indicating the existence of positive regulation $[25$, 26]. Although most of these sex-related genes have been detected in both sexes, different expression patterns have been observed between the two sexes. IAG, Sox, Dmrt, Dsx, Vasa, and S/x exhibit malebiased expression patterns and play crucial roles in testis development and spermatogenesis. CFSH, Fem1, FAMeT, Slo, Tra-2, BMPs, UCHLs, Erk2, Cdc2, EGFR, Vg, VgR, and VIH have higher expression levels in females and play important roles during ovarian development [21-23, 25, 27-29].

Therefore, identification of sex-related genes and characterization of their functions are crucial steps for understanding the sexual development mechanism. In the present study, we verified a female-specific locus named SNP1888 and a novel sex-related gene (Sp-Pol). The we mapped both SNP1888 and the gene on LG32 of a previously constructed high-density genetic map. In addition, the expression pattern of $S p-P o /$ in different tissues and different early development stages was analyzed. Finally, unilateral eyestalk ablation and fluorescence in situ hybridization $(\mathrm{FISH})$ were carried out to find out the regulation mechanism of $S p-P o l$. The present study provides novel insights into the sexual development mechanism of S. paramamosain. 


\section{Methods}

\section{Animals and sampling}

Samples including embryos, zoeae, megalopa, and crablets were obtained from a crab farm and aquatic product market in Chaozhou City, Guangdong Province of China. After transported to the laboratory, they were kept for adaption at room temperature. Then tissues including testis, ovary, heart, hepatopancreas, muscle, gill, thoracic ganglion, gut, and stomach were quickly dissected and stored in RNA keeper solution (Vazyme Biotech Co., Ltd, Nanjing, China) at $-80^{\circ} \mathrm{C}$ for RNA and DNA extraction. The total RNA was extracted using Trizol Reagent (Invitrogen, CA, USA) following the manufacturer's protocol. Firststrand cDNA was synthesized using ReverTra Ace® qPCR RT Master Mix with gDNA Remover (TOYOBO, Japan). Genomic DNA was extracted using TIANamp Marine Animals DNA kit (Tiangen Biotech Co. Ltd., Beijing, China) and treated with RNase $A$ to remove residual RNA.

\section{Verification of sex-specific SNP1888 and discovery of Sp- Pol gene}

A potential female-specific SNP locus named SNP1888 was identified from Cluster_39896 by RAD-seq in our previous study [10]. In order to verify SNP1888 is a real sex-specific locus, we first designed a pair of primers for PCR amplification, and then the PCR products of a total of 195 crabs ( 106 females and 89 males) were sequenced by bidirectional sequencing. The genotypes of SNP1888 were defined by the peak types according to the sequencing chromatograms: double peaks indicate heterozygous and single peak indicates homozygous. Based on gene clone technology and bioinformatics analysis, we identified a novel gene (designated as $S p-P o l$ ) at the upstream of SNP1888 (SNP1888 is located at the 3'-UTR of $S p-P o l)$.

\section{Cloning and sequence analysis of Sp-Pol}

Full-length $S p-P o /$ cDNA was achieved by the method of rapid amplification of cDNA $3^{\prime}$ and $5^{\prime}$ ends ( $3^{\prime}$ and 5' RACE) using a SMARTer RACE cDNA Amplification Kit (Clontech, USA) following the manufacturer's instructions. Nested PCR amplifications were performed using a universal primer mix (UPM outer primer) and a nested universal primer (NUP inner primer), in conjunction with two genespecific primers (GSPs) designed based on the cDNA sequence. All primers used are listed in Table 1. PCR was performed on an Eppendorf Mastercycler® ep realplex (Eppendorf, Germany) using the following conditions: denaturation at $94^{\circ} \mathrm{C}$ for $5 \mathrm{~min} ; 35$ cycles of amplification at $94^{\circ} \mathrm{C}$ for $30 \mathrm{~s}, 58^{\circ} \mathrm{C}$ for $30 \mathrm{~s}, 72^{\circ} \mathrm{C}$ for $30 \mathrm{~s}$ and final elongation at $72^{\circ} \mathrm{C}$ for $5 \mathrm{~min}$. The amplified products were purified and ligated into the Simple T1 vector (Transgen, Beijing). The recombinant plasmid was transformed into competent cell $E$. coli, and positive clones were sequenced. Later, the gene sequence was blasted with the NCBI database to find its homologs. 
Table 1

\begin{tabular}{|c|c|c|}
\hline Primer name & Sequence $\left(5^{\prime}-3^{\prime}\right)$ & Description \\
\hline Sp-Pol-F1 & CTACAGCACCCGCACCATCCCT & cDNA fragment verification \\
\hline Sp-Pol-R1 & TCCATGTCGGCGCAAACTTGCT & cDNA fragment verification \\
\hline Sp-Pol-F2 & GTCATTACCCGTTTTATCAACTCAC & DNA fragment verification \\
\hline Sp-Pol-R2 & GCCTTATGTCCTTATTCATTCCGT & DNA fragment verification \\
\hline 3' RACE-outer & ACAGCACCCGCACCATCCCTATCC & For 3' - RACE \\
\hline 3' RACE-inner & CCCACCGCCAACACACGGAAATCT & For 3' - RACE \\
\hline 5' RACE-outer & TGATGAGTGGACAGGCTGCTGATGG & For 5' - RACE \\
\hline 5' RACE-inner & AACAAGCAATCCATAATGACTCTG & For 5' - RACE \\
\hline RT-Sp-Pol-F & ATGTACTGGAAGCCATCCCTGAGAC & For qRT-PCR \\
\hline RT-Sp-Pol-R & CTCCCAGAGGTGTTAGACGAAGATTTAG & For qRT-PCR \\
\hline $18 S-F$ & GGGGTTTGCAATTGTCTCCC & For qRT-PCR \\
\hline 18S-R & GGTGTGTACAAAGGGCAGGG & For qRT-PCR \\
\hline$E F-1 a-F$ & CTACAAGTGTGGTGGCATCG & For qRT-PCR \\
\hline EF-1a-R & CGTCGATGATGGTCACGTAG & For qRT-PCR \\
\hline Sp-Pol- FISH & GCTAGAGCTTGCATCTCATTCCATGCTGCA & For FISH \\
\hline
\end{tabular}

\section{Localization of SNP1888 and Sp-Pol}

The sex-specific SNP1888 and Sp-Po/ were localized in the high-density genetic linkage map of $S$. paramamosain. The obtained genotypes of SNP1888 in the mapping family with a total of 129 individuals by PCR amplification and Sanger sequencing [10] were integrated with all SNP genotypes obtained in our previous study [11] to reconstruct the genetic map by Joinmap 5.0 software.

\section{Bioinformatic analysis}

The nucleotide sequence of $S p$-Po/ was compared with the sequences in GenBank using BLASTN and BLASTX (available at www.ncbi.nlm.nih.gov/blast), and the ORF was determined using Editseq (Lasergene, USA). The isoelectric point and molecular weight of the protein were predicted using the Compute pl/Mw tool (http://www expasy.org/tools/pi_tool.html). The potential N-glycosylation sites, Oglycosylation sites, and phosphorylation sites were predicted using NetNGlyc 1.0 Server (http://www.cbs.dtu.dk/services/NetNGlyc/), NetOGlyc 4.0 Server (http://www.cbs.dtu.dk/services/NetOGlyc/), and NetPhos 3.1 Server 
(http://www.cbs.dtu.dk/services/NetPhos/), respectively. Simple Modular Architecture Research Tool (SMART; http://smart.embl-heide lberg.de/) and SWISS-MODE (https://www.swissmodel.expasy.org/) were used to predict the three-dimensional (3D) protein structure and protein signal peptides and functional domains. The self-optimized prediction method with alignment (SOPMA) was employed to predict the secondary structure of a protein. Multiple sequence alignment of protein was performed using Bioedit software version 7.2 (http://bioedit.software.informer.com/7.2). The phylogenetic tree was constructed using Mega X software [30] (bootstrap analysis of 1,000 replicates) by the neighbour-joining method.

\section{Quantitative real-time PCR (qRT-PCR)}

The expression patterns of $\mathrm{Sp}$-Pol in different tissues (testis, ovary, heart, hepatopancreas, muscle, gill, thoracic ganglion, gut, and stomach) and different development stages were detected by qRT-PCR using SYBR Green method (Talent qPCR PreMix, TIANGEN Biotech (Beijing, China). The developmental stages of the ovary [31] and testis [32] were determined according to the size, colour, and morphology of gonads. qRT-PCR was performed using a LightCycler ${ }^{\circledR} 480$ Instrument II (Roche, Switzerland) with the following program: denaturation at $95^{\circ} \mathrm{C}$ for $3 \mathrm{~min} ; 40$ cycles of $95^{\circ} \mathrm{C}$ for $5 \mathrm{~s}, 60^{\circ} \mathrm{C}$ for $10 \mathrm{~s}$, and $72^{\circ} \mathrm{C}$ for $15 \mathrm{~s}$. The target gene $\mathrm{Sp}-\mathrm{Po}$ and the housekeeping genes (EF1 $\mathrm{a}$ and $18 \mathrm{~S}$ rRNA) were amplified using gene-specific primers (Table 1). Gene expression data were analyzed using the $2^{-\triangle \Delta C T}$ method [33].

\section{Unilateral eyestalk ablation}

Twenty males (mean weight $221.2 \pm 23.3 \mathrm{~g}$; testis stage III) and thirty females (mean weight $211.4 \pm 19.8$ g; ovary stage II) of $S$. paramamosain at the inter-moult stage were randomly distributed into the control group and experimental group. Before unilateral eyestalk ablation, crabs were held in captivity in $50 \mathrm{~L}$ aquariums with air-pumped circulating seawater for 7 days. The eyestalk of crabs was ablated using hot tweezers. No eyestalk was ablated in the individuals from the control group. After 7 days, gill, muscle, hepatopancreas, and gonads were dissected to investigate the expression level of Sp-Pol. After total RNAs extraction and CDNA synthesis, the SYBR Green method was performed using designed primers RTSp-Pol-F/R and 18S-F/R (Table 1). The procedure for qRT-PCR and data analyses were performed as described in section "Quantitative real-time PCR (qRT-PCR)".

Fluorescence in situ Hybridization (FISH)

After dissection, gonads samples (mean weight of male crabs: $107.4 \pm 23.1 \mathrm{~g}$; mean weight of female crabs: $124.8 \pm 21.9 \mathrm{~g}$ ) were used for the preparation of frozen sections. The OCT-embedding tissue was cut into $3 \mu \mathrm{m}$ sections by a frozen section machine (Thermo). The fluorescein-labelled DNA probe (5区FAM-GCTAGAGCTTGCATCTCATTCCATGCTGCA-3囚) was synthesized based on the CDNA sequence of $S p$ $\mathrm{Po} /$ by the Sangon Biotech Company (Shanghai, China) (Table 1). Before hybridization, slides were digested using proteinase $\mathrm{K}$ for $5 \mathrm{~min}$. Then, sections were immersed in $75 \%, 85 \%$, and $100 \%$ ethanol for $1 \mathrm{~min}$, respectively. Hybridization was carried out at $65^{\circ} \mathrm{C}$ overnight with FAM-labelled $S p$-Po/probe (10 $\mu \mathrm{l}$ for each slide). The sections were subjected to nuclear staining by DAPI and observed using Axio Observer 5 fluorescence microscopy (ZEISS, Germany). 


\section{Statistical analysis}

SPSS version 21.0 (Chicago, III., USA) was used for statistical analysis of the experimental data. The normality and homoscedasticity of the data were assessed using Kolmogorov-Smirnov and Levene's test, respectively. The proportional data were normalized using squareroot arcsin transformation. One-way ANOVA was utilized to determine the differences in the expression profile of $S p-P o /$ in different tissues and different developmental stages. Significant differences between groups were determined using the Tukey's HSD post hoc test in each case. The expression of $S p$-Po/ between unilateral eyestalk ablation and the control group was analyzed using an independent samples t-test. The level of significance for all analyses was set at $P<0.05$. All data are presented as mean $\pm \mathrm{SE}$.

\section{Results}

\section{Verification of sex-specific SNP1888}

The position of SNP1888 in Cluster_39896 is shown in Fig. 1A. With a pair of primers (F: CTACGGCACCCGCACCATCCTT, R: AGCAAGTTTGCGCCGACATGGA), a specific product was obtained by PCR. According to the sequencing chromatograms, SNP1888 showed heterozygous (T/C) in all 106 females and homozygous (C/C) in all 89 males (Fig. 1B, C).

\section{Characterization of Sp-Pol}

The full-length cDNA of Sp-Po/ was 1,703 bp and contains a 5区-UTR of $344 \mathrm{bp}$, a 3囚-UTR of $744 \mathrm{bp}$, and an ORF of 615 bp encoding a total of 204 amino acid residues (aa) (Fig. 2). Sp-Pol protein has a molecular mass of $22.74 \mathrm{kDa}$, with an estimated isoelectric point (PI) being 8.50. Analysis by SignalP 5.0 software revealed that the deduced peptide does not contain a putative signal peptide. Twenty-eight potential phosphorylation sites were identified at 14 serine residues (aa 6, 14, 25, 26, 29, 30, 31, 33, 40, 79, $100,101,131$, and 173) and 14 threonine residues (aa 19, 20, 22, 27, 28, 54, 59, 73, 80, 81, 127, 136, 164, and 195). A potential N-glycosylation site (162NQTC165) and six potential O-glycosylation sites (Ser6, Ser14, Thr19, Ser26, Thr-27, Thr148) were also identified. Using the SOPMA program reveal that the SpPol protein contained $33.82 \%$ a helix, $3.43 \% \beta$ turn, $55.39 \%$ random coil, and $7.35 \%$ extended chain (Fig. 3).

\section{Mapping of sex-specific SNP1888 and Sp-Pol}

The mapping results showed that the sex-specific SNP1888 with the Sp-Po/gene were mapped on LG32 of the sex-averaged high-density genetic linkage map (Fig. 4). Hence, LG32 is suggested as a sex-related linkage group due to it already has 13 sex-specific SNPs (SNP1888, SNP1, SNP2, SNP3, SNP4, SNP5, SNP6, SNP7, SNP8, SNP9, SNP10, SNP11, SNP12) and exclusive sex QTLs of S. paramamosain [11]. 


\section{Phylogenetic analysis of Sp-Pol protein}

Bioinformatics analysis of the deduced amino acid sequence of $\mathrm{Sp}$-Pol protein indicated its structural similarity to Gag-Pol polyprotein family of peptides. Sequence comparison demonstrated that the Sp-Pol protein shared the highest identity with the Retrovirus-related Pol polyprotein from transposon opus (Penaeus vannamei) (ROT64510.1, 60.47\% identity, bit score: 209, expectation value: $3.73 \mathrm{e}^{-61}$ ) (Fig. 5). A phylogenetic tree was constructed by the neighbor-joining method using multiple alignments of 26 homologous proteins from Decapoda, Insecta, Echinodermata, Cichliformes, and Octopoda (Fig. 6). In this tree, the homologous proteins are divided into four separate clades: Decapoda, Insecta, marine invertebrates (i.e., sea urchin, sea cucumber, coral, and octopus), and a fish species.

\section{Expression profile of Sp-Pol in different tissues and different developments}

Among all examined tissues, $S p-P o /$ was expressed at a higher level in gonads compared to other tissues $(P<0.05)$. The highest expression of $S p$-Pol was detected in testis with approximately 4 -fold higher than in the ovary $(P<0.05)$ (Fig. 7A). Meanwhile, we found that $S p$-Pol had mono-allelic expression in the ovary, whereas in the testis both alleles were expressed. In the ovary, mono-allele which owing nucleotide acid $C$ at the SNP1888 locus was expressed, and the other allele which owing $T$ was not expressed (Fig. 1B, C). Furthermore, the expression level of $S p$-Pol in different development stages of testis and ovary was investigated (Fig. 7B). The highest expression level of $\mathrm{Sp}$-Po/ was observed at the first stage of testis development (T-1), and then the expression level decreased significantly from T-1 to T-2 and T-3 ( $P<$ $0.05)$. However, in the ovary, the expression of $S p-P o /$ was low during all five stages of ovary development (0-1 to 0-5), even with the highest expression at 0-2. In addition, the expression profile of $\mathrm{Sp-Po/during}$ embryo (E), zoeae (Z-1 to Z-5), megalopa (M), and crablets (C-1 to C-6) was assessed (Fig. 7C, D). An upward trend was observed for males but a downward trend was observed for females at C-5 and C-6 stages $(P<0.05)$ (Fig. 7C). Sp-Pol was expressed in the embryo and all zoeae stages, with the highest expression at zoea I and embryo stage (Fig. 7D).

\section{The effects of eyestalk ablation on the expression level of Sp-Pol}

In males, eyestalk ablation significantly increased the expression level of $S p$-Po/ by 4.7 -fold and 2.1-fold in testis and hepatopancreas, respectively $(P<0.05)$ (Fig. 8A). In females, $S p$-Pol expression level was down-regulated in hepatopancreas by 2.2 -fold $(P<0.05)$ (Fig. 8B). Besides, eyestalk ablation slightly elevated the expression level of $S p$-Pol in the ovary by 1.5 -fold, however, no significant difference was found $(P=0.23)$. According to the result, $S p-P o /$ might be negative-regulated by eyestalk in testis, ovary, and male hepatopancreas, but not in female hepatopancreas. 


\section{The localization of Sp-Pol}

The FISH assay showed that $S p-P o /$ transcripts were detected in both ovary and testis (Fig. 9). In the ovary, $S p-P o /$ was mainly expressed in oogonia cells (Fig. 9A). In testis, $S p$-Po/transcripts were strongly localized in epithelial cells of seminiferous tubules (Fig. 9B).

\section{Discussion}

Limited information is available on the sex-determination system of brachyuran crabs. For decades, scientists believed that the $\mathrm{XY} / \mathrm{XX}$ sex-determination system is the only sex-determination system for crabs [34]. Recently, besides the XY/XX [9], the WZ/ZZ sex-determination system has been found in some crab species such as Eriocheir sinensis [8], S. paramamosain, S. tranquebarica, and S. serrata [10]. Sexspecific SNP marker is considered a powerful tool for understanding the sex-determination system [35]. Detection of female-specific SNP markers provides insights into a WZ/ZZ sex determination system in $S$. paramamosain [10]. In the present study, SNP1888 was mapped on the LG32 of the genetic map, which is a sex-related linkage group, and was located very close to the positions of other sex-specific SNPs (SNP1, SNP2, SNP3, SNP4, SNP5, SNP6, SNP7, SNP8, SNP9, SNP10, SNP11, SNP12) [10, 11]. The presence of female-specific SNP markers and their locations on the female linkage map supports the existence of a WZ/ZZ sex determination system in S. paramamosain.

Phosphorylation plays critical roles in several aspects of cell life, including metabolism, proliferation, apoptosis, differentiation, cell division, and DNA replication. Protein phosphorylation is catalyzed by a group of enzymes called kinases, which add a phosphate group to serine, threonine, tyrosine, or, to a lesser degree, histidine residues [36]. Twenty-eight putative phosphorylation sites (14 sites on serine and 14 sites on threonine residues) in Sp-Pol protein in the present study suggest that Sp-Pol protein may be activated by some kinases enzymes. The prediction of six potential O-glycosylation and one Nglycosylation site indicates that glycosylation may also affect the function of Sp-Pol protein. Glycosylation, like phosphorylation, is important due to the various roles in protein folding, protein trafficking and localization, cell-cell interactions, and epitope recognition [37]. Glycosylation can be classified into four types: N-linked, O-linked, Glypiation, and C-linked. In N-linked glycosylation, the oligosaccharide chain is attached to the amide nitrogen of asparagine. In O-linked glycosylation, the glycan is attached to the hydroxyl oxygen of serine or threonine [38].

Sequence homology and phylogenetic analysis showed that $\mathrm{Sp}$-Pol protein had the highest similarity to a Retrovirus-related Pol polyprotein gene from $P$. vannamei (60.47\% identity) and was also slightly homologous (20-35\% identity, bit score: $50-55$, expectation value: $\left.10^{-3}-10^{-6}\right)$ to a group of uncharacterized and hypothetical proteins from crustaceans, insects and echinoderms species. Although Sp-Pol protein was closely related to a Retrovirus-related Pol polyprotein from $P$. vannamei and a hypothetical protein from swimming crab (Portunustri tuberculatus), it was distinct from other identified 
proteins. The very low similarity of Sp-Pol protein to other known homologous proteins and failure to predict functional domains indicates that this gene may not belong to the Gag-Pol polyprotein family and can be reclassified as a new family. Notably, the protein encoded by the $S p$-Po/gene (204 aa) was quite smaller than Retrovirus-related Pol polyprotein from P. vannamei (541 aa) and other homologous proteins.

Spatio-temporal expression analysis showed that $S p-P o /$ was expressed in all the examined tissues and during all life stages, suggesting that it has a wide range of functions in different tissues and developmental stages. Expression of $S p$-Pol in gonads was higher than other tissues including heart, hepatopancreas, muscle, gill, thoracic ganglion, gut, and stomach. Comparing the expression of $\mathrm{Sp}-\mathrm{Pol}$ between females and males, male crabs displayed a higher level of $S p$-Pol expression in the testis compared to the ovary. The higher expression of $S p-P o /$ in testis revealed that it is likely to play more important roles in the sexual development of male compared to female S. paramamosain. The lower expression of $\mathrm{Sp}$-Po/ in the ovary compared to testis may due to the mono-allelically expression pattern of this gene in the ovary. In the ovary, mono-allele which owing nucleotide acid C at the SNP1888 locus was expressed, and the other allele which owing $T$ was not expressed. The mono-allele expression could result in several different outcomes at the transcriptional level. There is a general trend for monoallelically expressing cells to have fewer transcript levels than biallelically expressing cells [39].

Recently, several sexual genes have been identified to be involved in the "eyestalk-AG-testis" endocrine axis [15]. It has been revealed that some of these genes are regulated by the eyestalk neurohormones and are located at the upstream of $I A G$ and the sexual differentiation cascade [22, 23, 40-42]. For example, it has been reported that $C F S H$, Sox, Dsx, SIX,Dmrt, GEM, and Fem-1 are negatively regulated by the eyestalk (X-Organ).

Considering the important involvement of eyestalk (X-Organ) in the regulation of sex-related genes in male crustaceans, we hypothesized that eyestalk may participate in the regulation of $\mathrm{Sp}$ - $\mathrm{Pol}$, either directly or indirectly upstream of $S p$-Pol. Therefore, to evaluate the regulatory role of eyestalk in the regulation of $S p-P o l$, we investigated the expression level of $S p$-Pol after unilateral eyestalk ablation. After unilateral eyestalk ablation, the expression level of $S p$-Po/was significantly up-regulated in the testis and male hepatopancreas and downregulated in female hepatopancreas. A similar expression pattern has been reported for IAG in the male blue crab, Callinectes sapidus. The expression of IAG was found to be up-regulated after eyestalk ablation in testis and hepatopancreas [43]. The significant changes of $S p$-Pol mRNA in the hepatopancreas suggest $S p-P o /$ may be related to nutrient metabolism in the hepatopancreas. In decapods, the hepatopancreas is the major source for providing energy to gonad development [44]. The increase of hepatopancreas weight during the reproductive season has been documented in several studies (i.e., material and energy storage for oogenesis) [45]. Vitellin (Vn) produced in the hepatopancreas is the main component of yolk proteins, which is stored in oocytes and is a nutritional source for animal embryo growth [46]. $\mathrm{Vn}$ is processed from its precursor, vitellogenin $(\mathrm{Vg})$. In S. paramamosain, both the hepatopancreas and ovary are sites of $\mathrm{Vg}$ synthesis, but the hepatopancreas is the primary synthesis site [47]. Therefore, further studies are required to evaluate the 
role of $\mathrm{Sp}$-Pol in vitellogenesis and hepatic metabolism. Eyestalk ablation revealed that $\mathrm{Sp}$-Pol expression may be regulated by inhibitory factors present in the eyestalk ganglia.

To investigate the potential role of $S p$-Po/ in gametogenesis, we performed FISH to locate $S p-P o / m R N A$ in the ovary and testis. In the ovary, $S p$-Po/transcripts were detected in the oogonium cells but no signal was found in the follicle cells. In the testis, strong $S p$-Pol signals were detected in the epithelia of seminiferous tubules. Signals decreased toward the centre of the tubules of the testis, which means the expression level of $\mathrm{Sp}-\mathrm{Po} /$ may progressively decrease from spermatogonia to spermatids.

Spermatogenesis starts with the mitotic division of spermatogonia cells that locate on one side of the seminiferous tubules. Then, spermatogonia cells differentiate into primary spermatocytes.

Spermatocytes divide into two equal haploid spermatids by Meiosis II. Later, spermatids differentiate into spermatozoa in the central region of the tubule [48]. The role of the epithelium seminiferous tubules is not well studied in crustaceans. In fish, the cellular interactions between Sertoli cells and germ cells in the seminiferous epithelium play an important role during the spermatogenesis process [49]. The structure of seminiferous epithelium changes from a Sertoli cell monolayer (containing spermatogonia cells during the non-reproductive season) to an active spermatogenic arrangement composed of spermatocytes and spermatozoa that fill the tubular lumen (reproductive season) [50].

\section{Conclusions}

In the present study, we first verified SNP1888 being a female-specific SNP marker and then we identified a novel sex-related gene $(S p-P O I)$ at the upstream of SNP1888. Furthermore, we mapped SNP1888 and $\mathrm{Sp}$-Pol on a high-density genetic map. Despite the fact that $\mathrm{Sp}$-Pol protein has low homology to other homologous proteins in other species, Sp-Pol protein may not belong to the Gag-Pol polyprotein family and can be classified as a new family. $S p$-Polexhibited different expression patterns in different tissues, different early development stages. Sp-Po/ was expressed much higher in the testis than in the ovary, which might be related to the mono-allelically expression pattern of this gene in the ovary. The changes of $S p$-Pol expression in testis and hepatopancreas after eyestalk ablation showed that $S p$-Polis regulated by eyestalk neurohormones. These results demonstrated that $S p-P o /$ may play important roles in the sexual development of $S$. paramamosain.

Further studies are required to investigate the roles (i.e., long-term and short-term RNA interference) and regulation mechanism of $S p$-Polin $S$. paramamosain. It would be interesting to study the relationship of $S p-P o /$ with other sexual genes such as IAG, CFSH, Sox gene family, Dmrt gene family, etc. Based on the observation of mono-allelic expression of $S p$-Po/ in the ovary, it would be interesting to find whether $S p$ $P o /$ is an imprinted gene or regulate by DNA methylation mechanism.

\section{Declarations}

\section{Acknowledgments}




\section{Authors'contributions}

Ardavan Farhadi: Conceptualization, Data curation, Formal analysis, Investigation, Methodology, Visualization, Writing-original draft.

Xi Shi: Conceptualization, Data curation, Formal analysis, Investigation, Methodology.

Yin Zhang: Formal analysis, Investigation.

Huaiping Zheng, Shengkang Li, Yueling Zhang, and Mhd Ikhwanuddin: Validation. Hongyu Ma: Funding acquisition, Project administration, Resources, Supervision, Validation, Review \& editing

\section{Funding}

This work was supported by the National Key Research \& Development Program of China (No. 2018YFD0900201), National Natural Science Foundation of China (No. 31772837), the Leading Talent Project of Special Support Plan of Guangdong Province (2019TX05N067), the Science and Technology Project of Guangdong Province (2018A050506080), the "Sail Plan" Program for the Introduction of Outstanding Talents of Guangdong Province, China, and the STU Scientific Research Foundation for Talents (No. NTF17006).

\section{Availability of data and materials}

The datasets used and analyzed during the current study are available from the corresponding author on reasonable request.

\section{Ethics approval and consent to participate}

All experiments were performed according to recommendations in the Guide for the Care and Use of Laboratory Animals of Shantou University and with the approval of the Institutional Animal Care and Use Ethics Committee of Shantou University.

\section{Consent for publication}

Not applicable.

\section{Competing interests}


The authors declare that they have no competing interests.

\section{Author details}

${ }^{1}$ Guangdong Provincial Key Laboratory of Marine Biotechnology, Shantou University, Shantou, 515063, China. ${ }^{2}$ STU-UMT Joint Shellfish Research Laboratory, Shantou University, Shantou, 515063, China. ${ }^{3}$ Institute of Tropical Aquaculture and Fisheries, Universiti Malaysia Terengganu, Kuala Terengganu, 21030, Malaysia

\section{References}

1. Wang GZ, Li SJ, Zeng CS, Lin SJ, Kong XH, Ai CX, et al. Status of biological studies and aquaculture development of the mud crab, Scylla serrata, in China: an experimental ecological studies. Aquac Int. 2005;13:459-68.

2. Wu Q, Shi X, Fang S, Xie Z, Guan M, Li S, et al. Different biochemical composition and nutritional value attribute to salinity and rearing period in male and female mud crab Scylla paramamosain. Aquaculture. 2019;513:734417.

3. Shi X, Lu J, Wu Q, Waiho K, Aweya JJ, Fazhan H, et al. Comparative analysis of growth performance between female and male mud crab Scylla paramamosain crablets: Evidences from a four-month successive growth experiment. Aquaculture. 2019;505:351-62.

4. Li Y, Ai C, Liu L. Mud crab, Scylla paramamosain China's leading maricultured crab. Aquac China Success Stories Mod Trends. John Wiley \& Sons Ltd; 2018. p. 226-33.

5. Harlıoğlu MM, Farhadi A. Feminization strategies in crustacean aquaculture. Aquac Int. 2017;25:1453-68.

6. Chandler JC, Aizen J, Fitzgibbon QP, Elizur A, Ventura T. Applying the power of transcriptomics: understanding male sexual development in decapod Crustacea. Integr Comp Biol. Oxford University Press; 2016;56:1144-56.

7. Niiyama $\mathrm{H}$. The XY chromosomes of the shore-crab, Hemigrapsus sanguineus (de Haan). Jpn J Genet. 1938;14:34-8.

8. Cui Z, Hui M, Liu Y, Song C, Li X, Li Y, et al. High-density linkage mapping aided by transcriptomics documents ZW sex determination system in the Chinese mitten crab Eriocheir sinensis. Heredity (Edinb). Nature Publishing Group; 2015;115:206-15.

9. Fang S, Zhang Y, Shi X, Zheng H, Li S, Zhang Y, et al. Identification of male-specific SNP markers and development of PCR-based genetic sex identification technique in crucifix crab (Charybdis feriatus) with implication of an XX/XY sex determination system. Genomics. Elsevier; 2020;112:404-11.

10. Shi X, Waiho K, Li X, Ikhwanuddin M, Miao G, Lin F, et al. Female-specific SNP markers provide insights into a WZ/ZZ sex determination system for mud crabs Scylla paramamosain, $S$. 
tranquebarica and S. serrata with a rapid method for genetic sex identification. BMC Genomics. Springer; 2018;19:981-93.

11. Waiho K, Shi X, Fazhan H, Li S, Zhang Y, Zheng H, et al. High-density genetic linkage maps provide novel insights into ZW/ZZ sex determination system and growth performance in mud crab (Scylla paramamosain). Front Genet. Frontiers; 2019;10:298-314.

12. Ventura T, Sagi A. The insulin-like androgenic gland hormone in crustaceans: From a single gene silencing to a wide array of sexual manipulation-based biotechnologies. Biotechnol Adv. 2012;30:1543-50.

13. Zmora N, Chung JS. A novel hormone is required for the development of reproductive phenotypes in adult female crabs. Endocrinology. 2014;155:230-9.

14. Rosen O, Manor R, Weil S, Gafni O, Linial A, Aflalo ED, et al. A sexual shift induced by silencing of a single insulin-like gene in crayfish: ovarian upregulation and testicular degeneration. PLoS One. 2010;5:p.e15281.

15. Guo Q, Li S, Lv X, Xiang J, Manor R, Sagi A, et al. Sex-Biased CHHs and Their Putative Receptor Regulate the Expression of IAG Gene in the Shrimp Litopenaeus vannamei. Front Physiol. Frontiers; 2019;10:1525.

16. Ma K, Qiu G, Feng J, Li J. Transcriptome analysis of the oriental river prawn, Macrobrachium nipponense using 454 pyrosequencing for discovery of genes and markers. PLoS One. Public Library of Science; 2012;7:e39727.

17. Jin S, Fu H, Zhou Q, Sun S, Jiang S, Xiong Y, et al. Transcriptome analysis of androgenic gland for discovery of novel genes from the oriental river prawn, Macrobrachium nipponense, using illumina hiseq 2000. PLoS One. 2013;8.

18. Chandler JC, Elizur A, Ventura T. The decapod researcher's guide to the galaxy of sex determination. Hydrobiologia. Springer; 2018;825:61-80.

19. Yang X, Ikhwanuddin M, Li X, Lin F, Wu Q, Zhang Y, et al. Comparative transcriptome analysis provides insights into differentially expressed genes and long non-coding RNAs between ovary and testis of the mud crab (Scylla paramamosain). Mar Biotechnol. 2018;20:20-34.

20. Zhang Y, Miao G, Wu Q, Lin F, You C, Wang S, et al. Transcriptome sequencing and molecular markers discovery in the gonads of Portunus sanguinolentus. Sci data. Nature Publishing Group; 2018;5:180131.

21. Jin S, Hu Y, Fu H, Jiang S, Xiong Y, Qiao H, et al. Potential functions of Gem-associated protein 2-like isoform X1 in the oriental river prawn Macrobrachium nipponense: cloning, qPCR, in situ hybridization, and RNAi analysis. Int J Mol Sci. Multidisciplinary Digital Publishing Institute; 2019;20:3995.

22. Shi L, Han S, Fei J, Zhang L, Ray JW, Wang W, et al. Molecular characterization and functional study of insulin-like androgenic gland hormone gene in the red swamp crayfish, Procambarus clarkii. Genes (Basel). 2019;10:645. 
23. Zheng J, Cheng S, Jia Y, Gu Z, Li F, Chi M, et al. Molecular identification and expression profiles of four splice variants of Sex-lethal gene in Cherax quadricarinatus. Comp Biochem Physiol B. 2019;234:26-33.

24. Jiang Q, Lu B, Wang G, Ye H. Transcriptional inhibition of $S p-I A G$ by crustacean female sex hormone in the mud crab, Scylla paramamosain. Int J Mol Sci. 2020;21:5300.

25. Abayed FAA, Manor R, Aflalo ED, Sagi A. Screening for Dmrt genes from embryo to mature Macrobrachium rosenbergii prawns. Gen Comp Endocrinol. 2019;282:113205.

26. Tan K, Li Y, Zhou M, Wang W. siRNA knockdown of MrIR induces sex reversal in Macrobrachium rosenbergii. Aquaculture. Elsevier; 2020;735172.

27. Xu YR, Wang GY, Zhou YC, Yang WX. The characterization and potential roles of bone morphogenetic protein 7 during spermatogenesis in Chinese mitten crab Eriocheir sinensis. Gene. 2018;673:119-29.

28. Zhou LX, Liu X, Ye BQ, Liu Y, Tan SP, Ma KY, et al. Molecular characterization of ovary-specific gene Mrfem-1 and siRNA-mediated regulation on targeting Mrfem- 1 in the giant freshwater prawn, Macrobrachium rosenbergii. Gene. 2020;754:144891.

29. Jiang Q, Lu B, Lin D, Huang H, Chen X, Ye H. Role of crustacean female sex hormone (CFSH) in sex differentiation in early juvenile mud crabs, Scylla paramamosain. Gen Comp Endocrinol. Elsevier; 2020;113383.

30. Kumar S, Stecher G, Li M, Knyaz C, Tamura K. MEGA X: molecular evolutionary genetics analysis across computing platforms. Mol Biol Evol. Oxford University Press; 2018;35:1547-9.

31. Wu Q, Waiho K, Huang Z, Li S, Zheng H, Zhang Y, et al. Growth performance and biochemical composition dynamics of ovary, hepatopancreas and muscle tissues at different ovarian maturation stages of female mud crab, Scylla paramamosain. Aquaculture. 2020;515:734560.

32. Waiho K, Fazhan H, Jasmani S, Ikhwanuddin M. Gonadal development in males of the orange mud crab, Scylla olivacea (Herbst, 1796)(Decapoda, Brachyura, Portunidae). Crustaceana. Brill; 2017;90:1-19.

33. Livak KJ, Schmittgen TD. Analysis of relative gene expression data using real-time quantitative pcr and the 2(-delta delta $\mathrm{c}(\mathrm{t})$ ). Methods. 2001;25:402-8.

34. Legrand JJ, Legrand-Hamelin E, Juchault P. Sex determination in Crustacea. Biol Rev. Wiley Online Library; 1987;62:439-70.

35. Pan ZJ, Li XY, Zhou FJ, Qiang XG, Gui JF. Identification of sex-specific markers reveals male heterogametic sex determination in Pseudobagrus ussuriensis. Mar Biotechnol. Springer; 2015;17:441-51.

36. Song J, Wang H, Wang J, Leier A, Marquez-Lago T, Yang B, et al. PhosphoPredict: A bioinformatics tool for prediction of human kinase-specific phosphorylation substrates and sites by integrating heterogeneous feature selection. Sci Rep. Nature Publishing Group; 2017;7:1-19.

37. Caragea C, Sinapov J, Silvescu A, Dobbs D, Honavar V. Glycosylation site prediction using ensembles of support vector machine classifiers. BMC Bioinformatics. Springer; 2007;8:1-13. 
38. Julenius K, Mølgaard A, Gupta R, Brunak S. Prediction, conservation analysis, and structural characterization of mammalian mucin-type O-glycosylation sites. Glycobiology. Oxford University Press; 2005;15:153-64.

39. Eckersley Maslin MA, Spector DL. Random monoallelic expression: regulating gene expression one allele at a time. Trends Genet. 2014/04/26. 2014;30:237-44.

40. Shen H, Hu Y, Zhou X. Sex-lethal gene of the Chinese mitten crab Eriocheir sinensis: cDNA cloning, induction by eyestalk ablation, and expression of two splice variants in males and females. Dev Genes Evol. Springer; 2014;224:97-105.

41. Ma KY, Liu ZQ, Lin JY, Li J Le, Qiu GF. Molecular characterization of a novel ovary-specific gene fem-1 homolog from the oriental river prawn, Macrobrachium nipponense. Gene. 2016;575:244-52.

42. Zhong P, Zhou T, Zhang Y, Chen Y, Yi J, Lin W, et al. Potential involvement of a DMRT family member $(M r-D s x)$ in the regulation of sexual differentiation and moulting in the giant river prawn Macrobrachium rosenbergii. Aquac Res. 2019;50:3037-49.

43. Chung JS, Manor R, Sagi A. Cloning of an insulin-like androgenic gland factor (IAG) from the blue crab, Callinectes sapidus: implications for eyestalk regulation of IAG expression. Gen Comp Endocrinol. Elsevier; 2011;173:4-10.

44. Sokolowicz CC, Bond-Buckup G, Buckup L. Dynamics of gonadal development of Aegla platensis Schmitt (Decapoda, Anomura, Aeglidae). Rev Bras Zool. SciELO Brasil; 2006;23:1153-8.

45. Farhadi A, Harlıoğlu MM. The annual cycle of spermatozoa content in the vas deferens and some reproductive parameters in the narrow-clawed crayfish Pontastacus leptodactylus (Eschscholtz, 1823). Aquac Reports. 2019;13:p.100185.

46. Tseng DY, Chen YN, Kou GH, Lo C-F, Kuo CM. Hepatopancreas is the extraovarian site of vitellogenin synthesis in black tiger shrimp, Penaeus monodon. Comp Biochem Physiol A Mol Integr Physiol. 2001;129:909-17.

47. Huang $X$, Feng $B$, Huang $H$, Ye $H$. In vitro stimulation of vitellogenin expression by insulin in the mud crab, Scylla paramamosain, mediated through PI3K/Akt/TOR pathway. Gen Comp Endocrinol. Elsevier; 2017;250:175-80.

48. Zhang EF, Qiu GF. A novel Dmrt gene is specifically expressed in the testis of Chinese mitten crab, Eriocheir sinensis. Dev Genes Evol. Springer; 2010;220:151-9.

49. Batlouni SR, Nóbrega RH, França LR. Cell junctions in fish seminiferous epithelium. Fish Physiol Biochem. Springer; 2009;35:207-17.

50. Batlouni SR, Romagosa E, Borella MI. The reproductive cycle of male catfish Pseudoplatystoma fasciatum (Teleostei, Pimelodidae) revealed by changes of the germinal epithelium: an approach addressed to aquaculture. Anim Reprod Sci. Elsevier; 2006;96:116-32.

\section{Figures}


SNP1888-Cluster_39896

\begin{tabular}{|c|c|c|c|c|c|}
\hline 1 & CACCCTTCGA CACACCAATT & AGGCATCAAG & CTCATTGCAG & CCAATGGAAG & САСАAТTСCС \\
\hline 61 & ACCTACGGCA CCCGCACCAT & ССТТАТССАА & ACAGCTGAAC & GCAGCTTTTC & TTGGGATTTC \\
\hline 121 & ATCATCACCG ACGTCAAGAC & АССТСТССТА & GGAGTGGATT & TCCAGAGTCA & TTATGGATTG \\
\hline 181 & CTTGTTGATG TCACCAACCA & TAAATTGCTG & GATGTAGCAA & CGTTCCGCTC & АACACСТСТT \\
\hline 241 & GGCTCCCACC GCCAACACAC & GGAAATCTGT & TCATTGAGAA & CAGATACCCC & TTATGACATG \\
\hline 301 & CTCAGACAAG AATTGCAGT & & & & \\
\hline
\end{tabular}

A

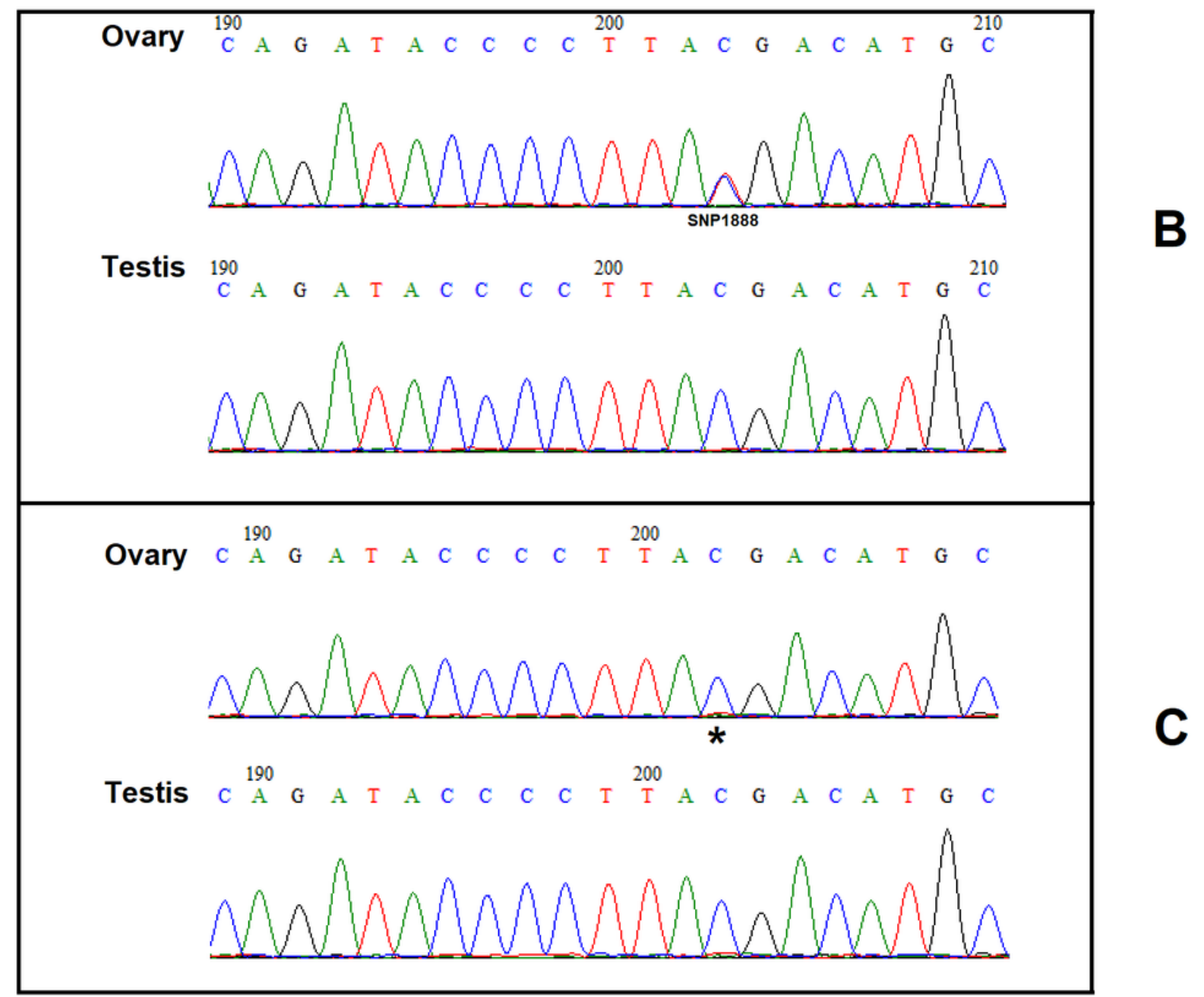

Figure 1

A. The position of Seq-1888 and its sex-specific SNP marker on the sequence (SNP 1888:T/C).

Sequencing chromatograms of the ovary and testis DNA (Figure 1B) and cDNA (Figure 1C) in Scylla paramamosain. Double peaks indicate heterozygous and single peak indicates homozygous. Sequencing data (i.e., sequencing data for SNP discovery) are available at NCBI Sequence Read Archive (accession number SRP135178). 
ACATGGGCGTTTTATCAACTCACTGCATTATTTGCATAGGGTTTCAAGATTTGTATATTTATATCTAGTATGGTG TTTGTTATGTATGCTCAAGGTGTGAATCAACCTCATCCAACCGGAACACTCAACTTTCTCTTCAACCTCAACAAC TGGTGACCCCTGGACAAGAAACTACTCTTCAGCAATGGAAGAAGATACCAAGCCCAGCAATGCAAAACCAACCGC TTCCACCGTCACAGTGAAGCTGTCACCCTTCTGCGCCAGTGAGGCTGCATCATGGTTTCGGCGAGCAGAAGTTCA ATTCCGACTGAGGAAAGTTACAAGCCCTCAAACCAAGGCCGACTATGTACTGGAAGCCATCCCTGAGACAATTTT AGTTCACGATCTCCGTCAGCGCCTGGCTCCGACGTCCTCTAAATCTTCGTCTAACACCTCTGGGAGACACCACAG CACATGCAGCATGGAATGAGATGCAAGCTCTAGCTACACTACTTGAACATGACTCTACTACTGGCAAACCACAGC GGGTAGACTTGCTGTGGGAGCTGTGGCTGCAACGTCTTCCCTCATCTGTGAGAGCTGCCCTACACGAAGCTGATG ACTGCCCCGTGGAAGAGCTCATAAATAAGGTGGACAATCTTATCAATACCGCAAAAGCGTCCTGTGCCCCCGACA $\begin{array}{lllllllllllllllllllllllll}D & C & P & V & \text { E } & \text { E } & \text { L } & \text { I } & N & K & V & \text { D } & \text { N } & \text { L } & \text { I } & N & \text { T } & \text { A } & \text { K } & \text { A } & \text { S } & \text { C } & \text { A } & \text { P } & \text { D }\end{array}$ CTATCTGCCCTGCCTTAGTTGACAACCTGCCCAACACCAATGCTGCCAGGCCACCTGTTTGCAAGTGGCTGCCCG \begin{tabular}{lllllllllllllllllllllllll}
\hline & $\mathrm{I}$ & $\mathrm{C}$ & $\mathrm{P}$ & $\mathrm{A}$ & $\mathrm{L}$ & $\mathrm{V}$ & $\mathrm{D}$ & $\mathrm{N}$ & $\mathrm{L}$ & $\mathrm{P}$ & $\mathrm{N}$ & $\mathrm{T}$ & $\mathrm{N}$ & $\mathrm{A}$ & $\mathrm{A}$ & $\mathrm{R}$ & $\mathrm{P}$ & $\mathrm{P}$ & $\mathrm{V}$ & $\mathrm{C}$ & $\mathrm{K}$ & $\mathrm{W}$ & $\mathrm{L}$ & $\mathrm{P}$
\end{tabular} ACAACCAGACGTGCAACTGCAAACCAGGAGTTTCCAGCCAACATGGACAGCATGGACTGTGCTACTACCATCACA

901 $\begin{array}{lllllllllllllllllllllllll}D & N & Q & T & C & N & C & K & P & G & V & S & S & Q & H & G & Q & H & G & L & C & Y & Y & H & H\end{array}$ AATTCGGAGCTGGAGCTTGCAAATGCACCCCAGGTTGCCAGTGGCCAAAAAACTGTTAATGAGGCCACCACTGAC $\begin{array}{llllllllllllllllllll}K & F & G & A & G & A & C & K & C & T & P & G & C & Q & W & P & K & N & C & *\end{array}$ CACAGCAGTGGCCTCTTCGGACCCCAAGCCTGGGAATATCAATGCGCTTGCTTTACCAGCCTCTGGTTTCTTCAT CACAGACATCTTATCTGGCTGTAAGTTTCTGGTGGACACAGGCACTTTTTGTTTCCTGTTTCCAGTCACAGCAGA GGACAGAAACTGCCCTTTGACACACTGATTAGACATCAAGCTCATCGCAGCCAATGGAAGTACAATTCCCACCTA CAGCACCCGCACCATCCCTATCCAAGCAGTCGAACGCAGCTTTTCTTGGGATTTCATCATCACCGACGTCAAGAC

1351

1426 ACCTCTCCTAGGAGTGGATTTCCAGAGTCATTATGGATTGCTTGTTGATGTCACCAACCATAAATTGCTGGATGT AGCAACGTTCCGCTCAACACCTCTTGGCTCCCACCGCCAACACACGGAAATCTGTTCATTGAGAACAGATACCCC TTAGGACATGCTCAGACAAGAATTCCCTGAAGTATTCCACCTAGAACTCCATCAGCAGCCTGTCCACTCATCAAA ACATGGAATTTTCCACTACATCAAAACAACAGGTCCCCCGGTTCATTCCAAGTTTAGACGGCTATCCCCTGAAGA ACTTCAAGCAGCAAGTTTGCGCCGACATGGAACAAATGGGCATATGTCAGAAGGCCTCGAGTCCATGGGCATCTT CCCTTCACCTTGTCAAGAATCTTTTAGAAAAAAAAAAAAAAAAAAAAAAAAAA

\section{Figure 2}

Sequences of full-length complementary DNA and deduced amino acids (aa) of Sp-Pol. The number of nucleotide and amino acid are listed on the left side. Start (ATG) and stop codon (TAA) of the open reading frame are both indicated in bold. Termination of aa is denoted by asterisks. Predicted Oglycosylation sites are indicated by red solid triangles $(\boldsymbol{\Lambda})$. The potential $\mathrm{N}$-glycosylation site (162NQTC165) is underlined. Potential phosphorylation sites are in boxes. Letter with green background indicates the location of sex-specific SNP (SNP1888: C/T). 


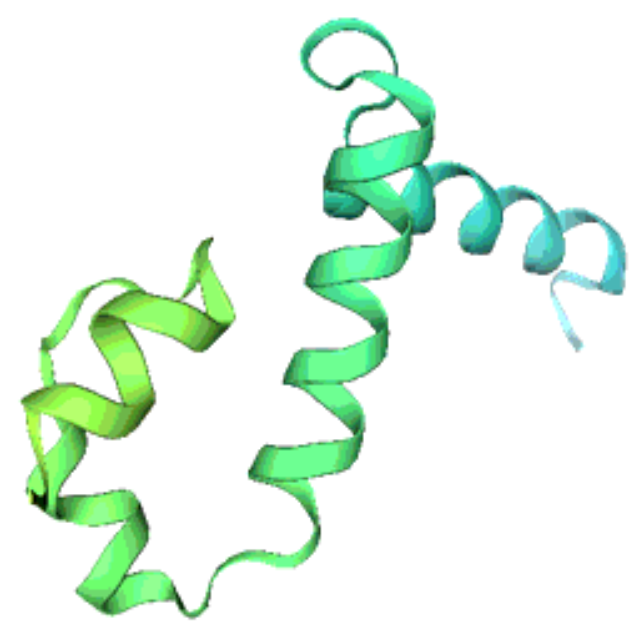

A

B
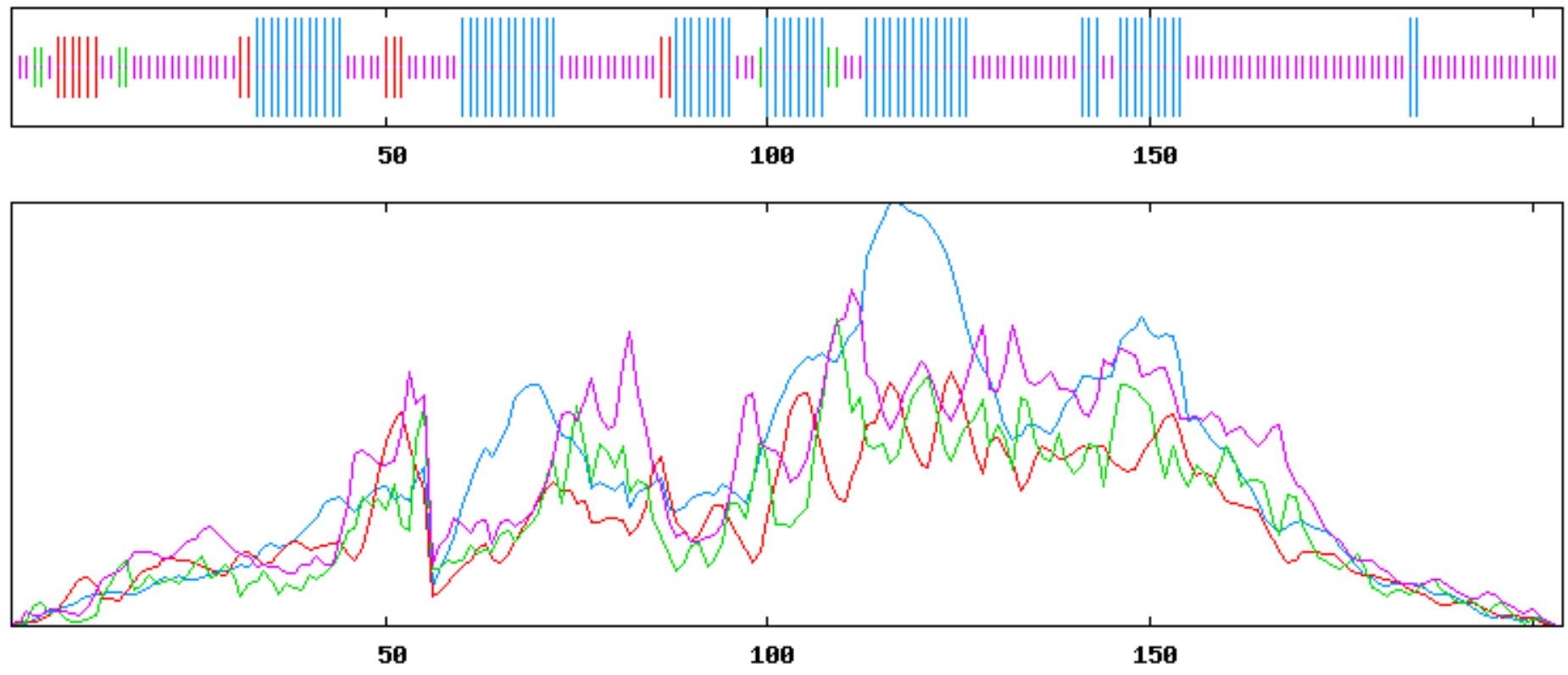

Figure 3

Illustration of the Sp-Pol protein. (A) The three-dimensional (3D) protein structure of Sp-Pol. (B) Analysis of the secondary structure. The a-helix (blue), extended strand (red), random coil (yellow), and b-turn (green) are indicated by blue. 


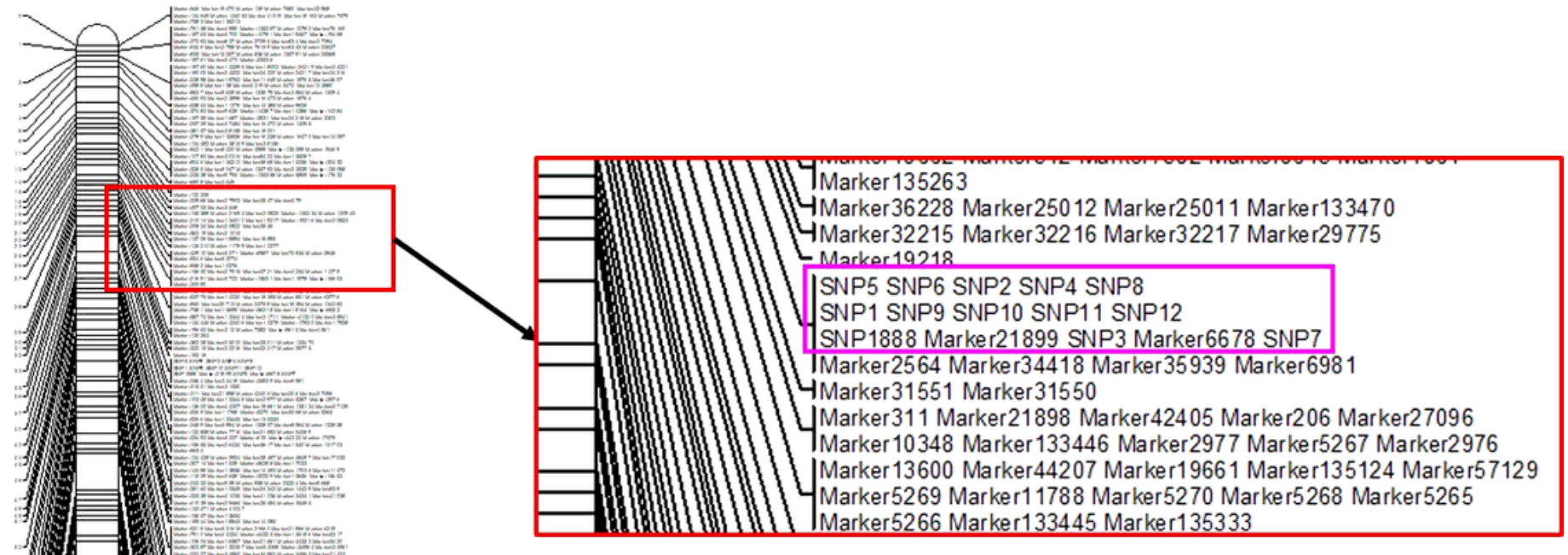

Figure 4

Mapping results of Sp-Pol gene (SNP1888) in the genetic map of Scylla paramamosain. 
Scylla paramamosain Penaeus vannamei Portunustri tuberculatus Clustal Consensus

Scylla paramamosain Penaeus vannamei Portunustri tuberculatus Clustal Consensus

Scylla paramamosain Penaeus vannamei

Portunustri tuberculatus Clustal Consensus

Scylla paramamosain Penaeus vannamei Portunustri tuberculatus Clustal Consensus

Scylla paramamosain Penaeus vannamei

Portunustri tuberculatus Clustal Consensus

Scylla paramamosain Penaeus vannamei Portunustri tuberculatus Clustal Consensus

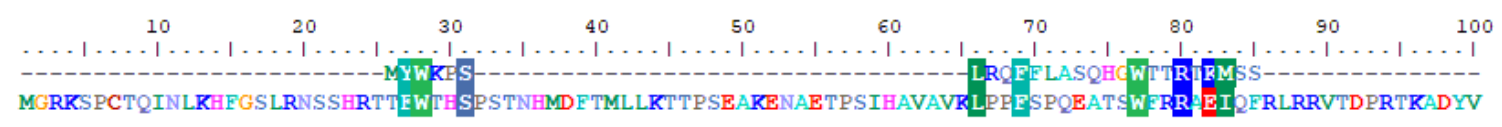

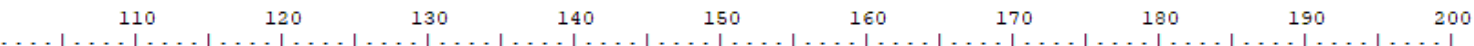

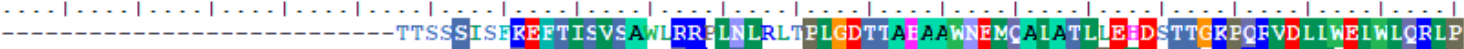

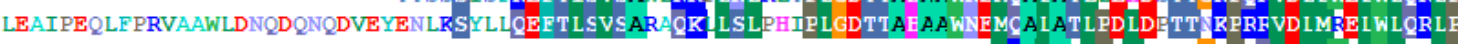
-
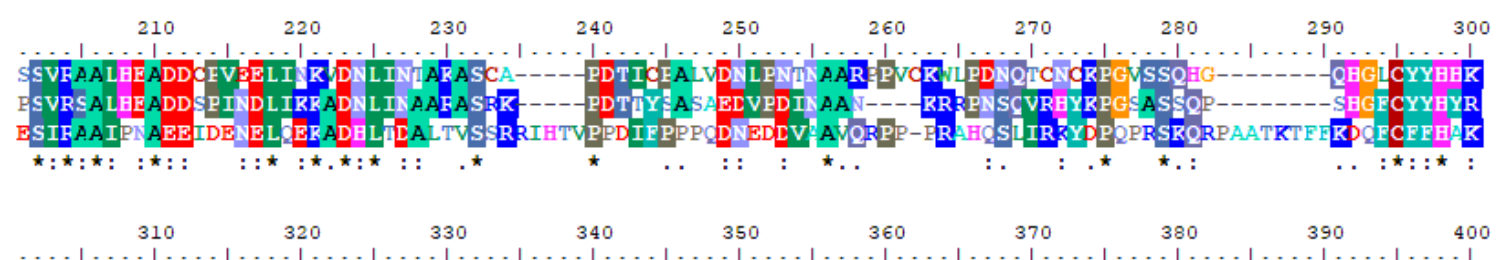

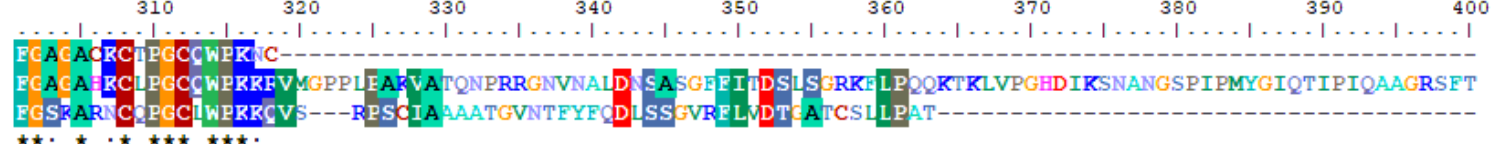

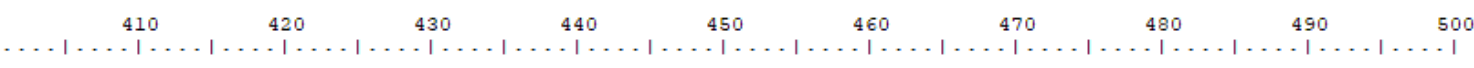
WDFIIADVKT P LLGADF LGHHG LLVDVANRRLLDVTTFCSTPLGSNHQYTEICTVRADTPYDS LCKEYPDVERPELRQQPGQPAKHGIFHYIKTTGPPVH

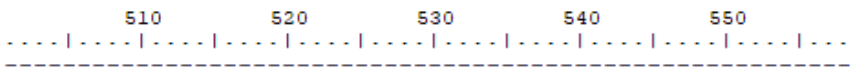

SRFRLLSPEKLQAAKQAYSEMERMGICQKASS PWA.SPLHLVRKPEGTWRHVVTIGVLT

\section{Figure 5}

Multiple alignments of deduced amino acids of Sp-Pol protein and its homologs. (A): GenBank accession numbers are as follows: Penaeus vannamei (ROT64510.1); Portunustri tuberculatus (MPC10902.1). (B): The three-dimensional (3D) protein structure of Sp-Pol protein predicted by the online server SWISSMODEL. 


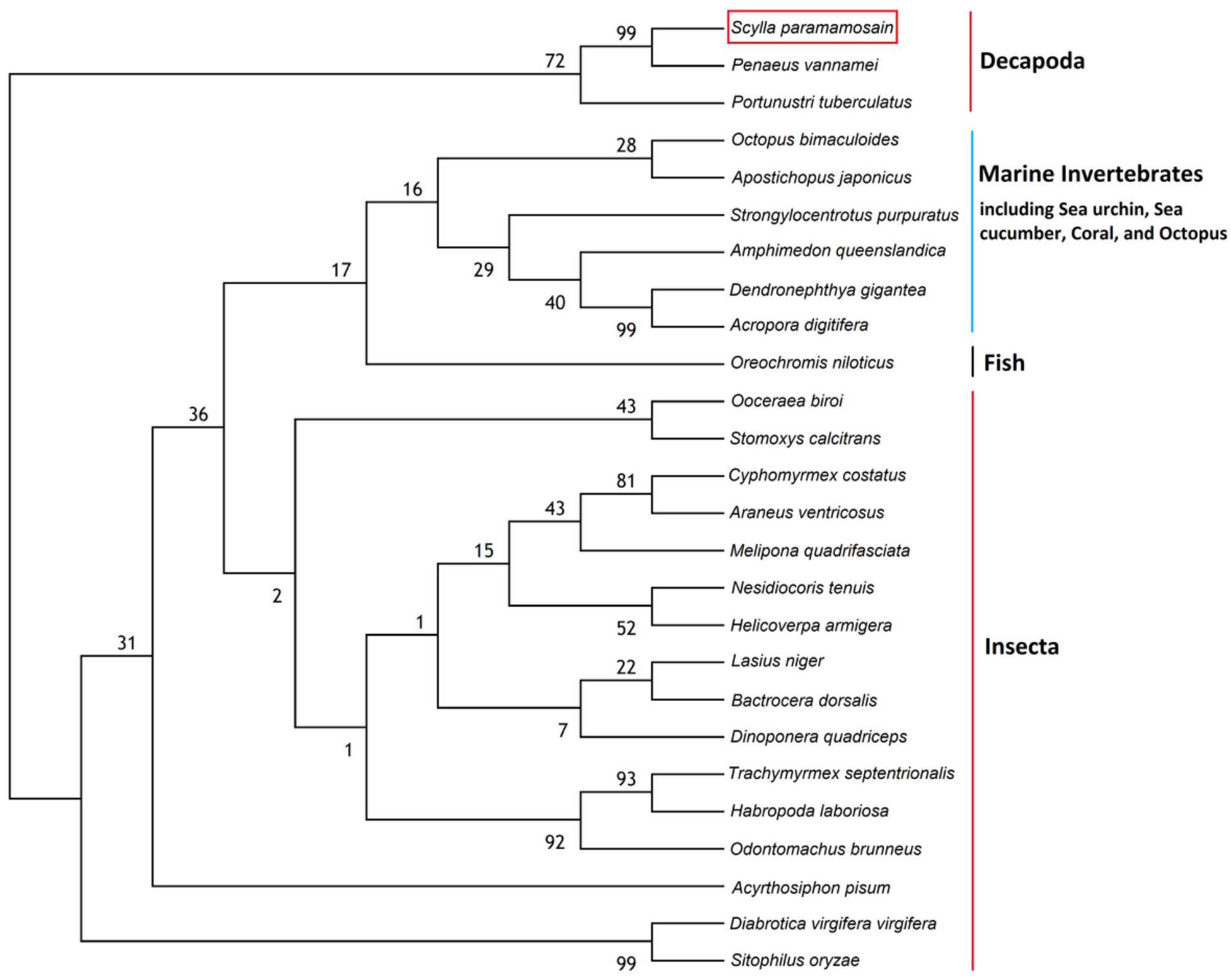

\section{Figure 6}

Phylogenetic analysis of Sp-Pol protein (red rectangle) from S. paramamosain and homologous proteins from other species. The amino acid sequence and GenBank accession number of the proteins are provided in the supplementary file. 

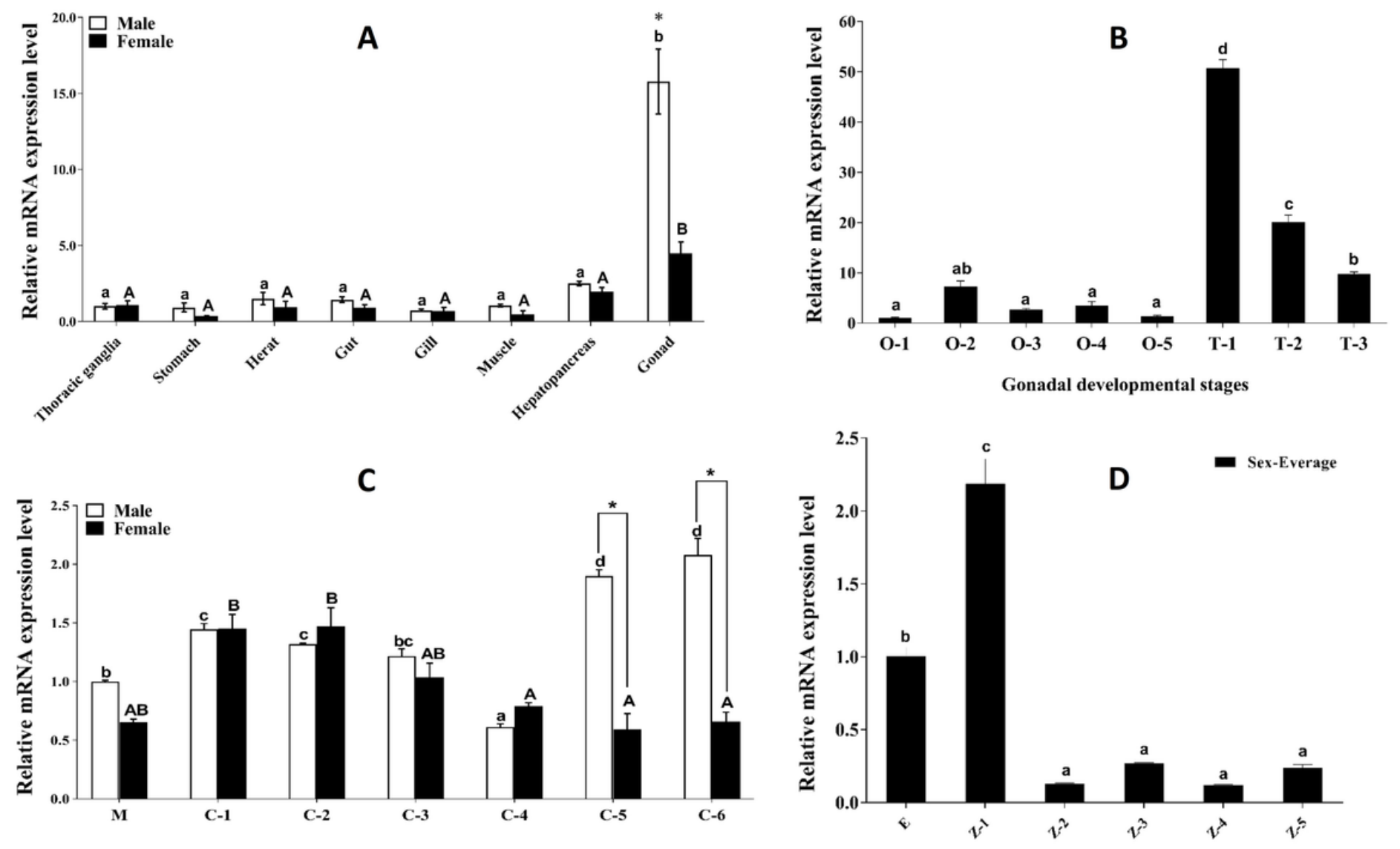

Figure 7

The expression profiles of Sp-Pol in different tissues and different sexual developmental stages. (A): The expression of Sp-Pol mRNA in different tissues. (B): The expression of Sp-Pol mRNA at different gonadal development stages (O, ovary; $\mathrm{T}$, testis). (C): The expression of Sp-Pol mRNA during different juvenile stages ( $M$, megalopa larva stage; $C$, crablet stage). (D): The expression of Sp-Pol mRNA during larvae development (E, eggs hatch; $Z$, zoea stage). Significant differences are indicated with different letters and * mark $(P<0.05)$. Values are mean $( \pm S E)$.

A

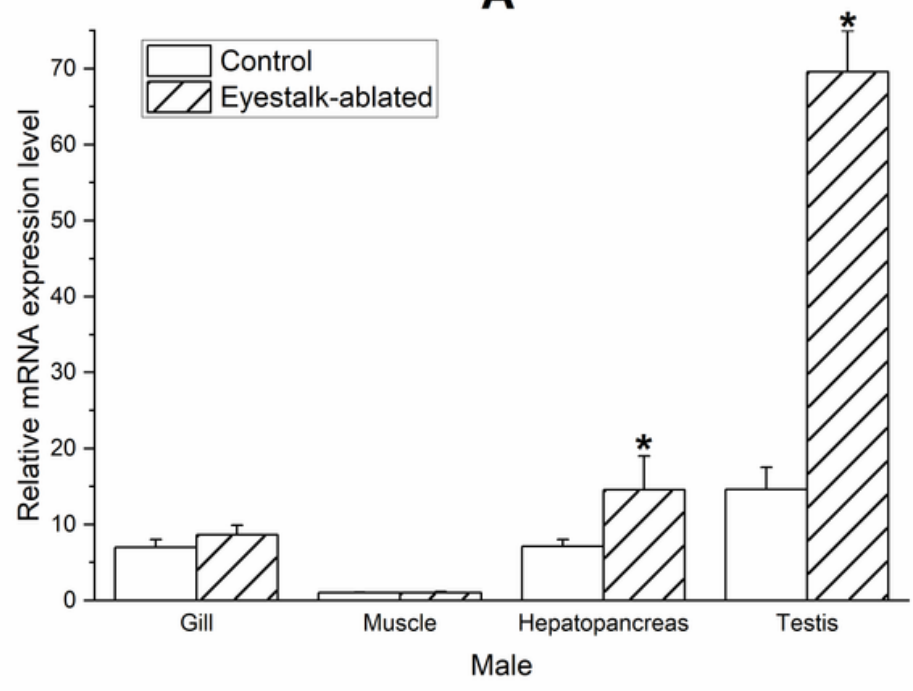

B

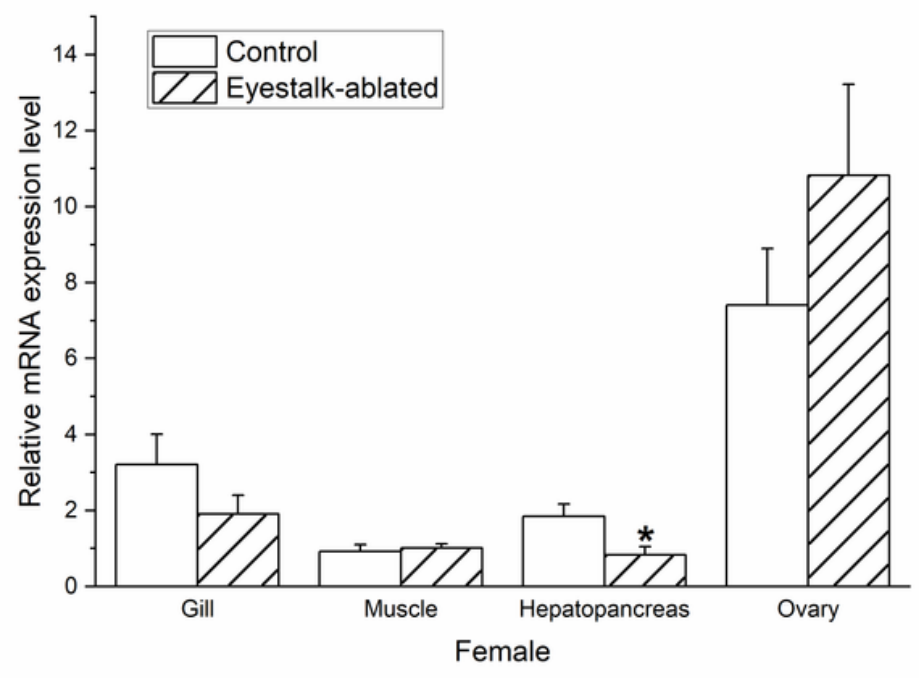




\section{Figure 8}

Effect of unilateral eyestalk ablation on Sp-Pol expression in different tissues. * indicates significant expression difference $(P<0.05)$. Values are mean $( \pm S E)$.

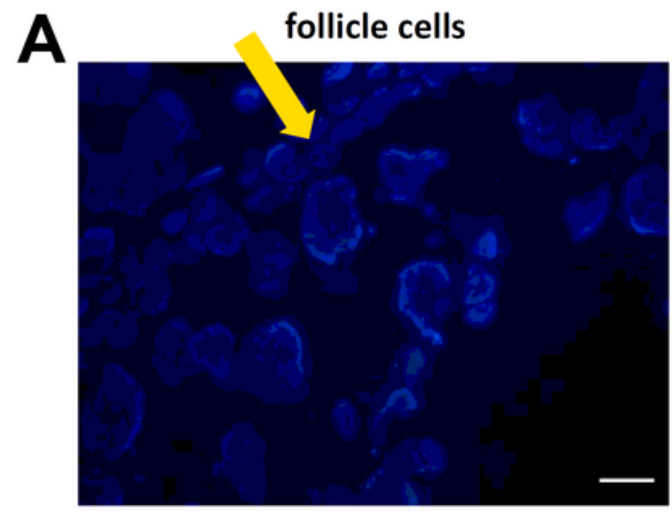

Nuclear staining by DAPI

B

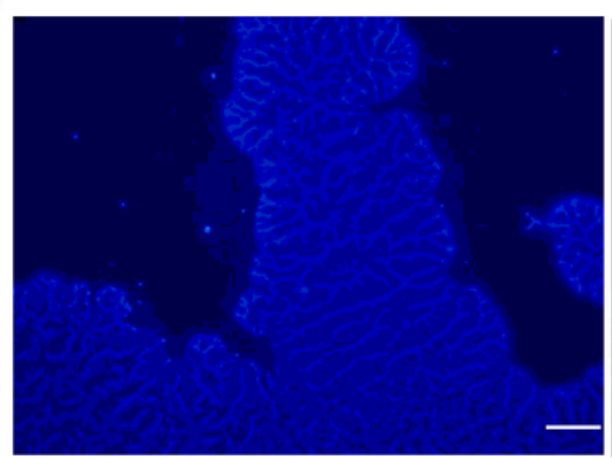

Nuclear staining by DAPI

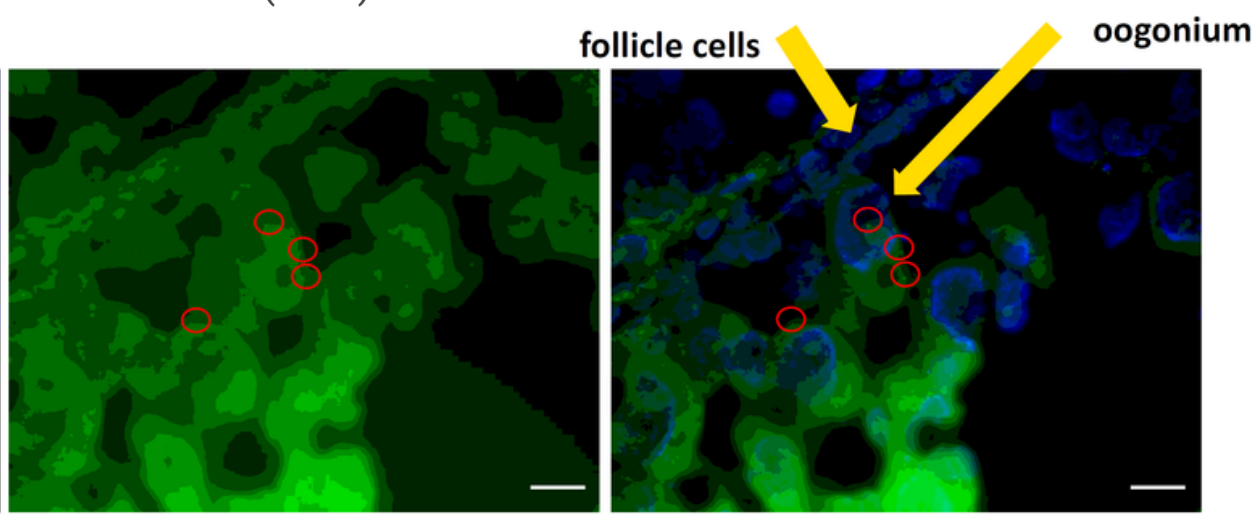

Localization of Sp-pol transcripts Merged image of Sp-pol and DAPI staining

Epithelia of seminiferous tubules

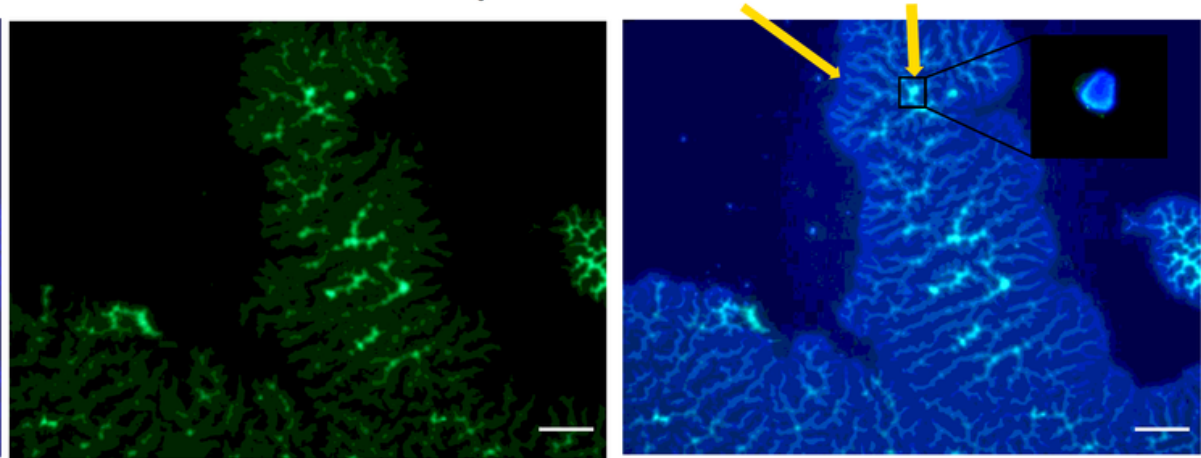

Localization of Sp-pol transcripts Merged image of Sp-pol and DAPI staining

\section{Figure 9}

Localization of Sp-Pol transcripts in the ovary (A) and testis (B) of Scylla paramamosain by FISH. Image $A$ and $B$ were captured at $\times 100$ and $\times 10$ magnification, respectively. Sp-Pol mRNA signals (green dots) are presented inside the red circles.

\section{Supplementary Files}

This is a list of supplementary files associated with this preprint. Click to download.

- S1file.docx 